\title{
Failure Process and Support Method of Roadways Excavated in Inclined Rockmass Strata
}

\author{
Jinhai Gao ${ }^{1,2}$, H. Y. Liu ${ }^{1, *}$, Mingjian Zhang ${ }^{3}$, M. M. A. Aziz ${ }^{4}$ \\ ${ }^{1}$ School of Engineering and ICT, University of Tasmania, Hobart, TAS7001, Australia \\ ${ }^{2}$ Henan Polytechnic University, Jiaozuo, Henan, 454000, China \\ ${ }^{3}$ The Second Coal Mine of Zhaogu, Henan Coal Chemical Industry Group Co. Ltd, China \\ ${ }^{4}$ Faculty of Civil Engineering, Universiti Teknologi Malaysia, 81310 Skudai, Johor, Malaysia \\ *Corresponding Author: Hong.Liu@utas.edu.au
}

Copyright (C) 2014 Horizon Research Publishing All rights reserved.

\begin{abstract}
A three-dimensional geomechanical physical model is first constructed according to the similar simulation theory for a roadway excavated in inclined rock mass strata. The similar simulation model is then loaded in the laboratory using a self-designed YDM-E physical model testing device to observe the stress distribution and associated failure process of the roadway. For the roadway excavated in the rockmass strata with an inclined angle of $25^{\circ}$, it is found that cracks are initiated firstly in the rockmass located in the right-upper corner of the roadway and then propagate and coalesce resulting in that the rock located in the right-upper corner of the roadway detaches from the roof and falls into the roadway causing the collapse of the roadway. An unsymmetrical supporting scheme is then proposed to use cablebolts to supplement the regular support system of shotcrete lining and rockbolts for the roadway excavated in the inclined rock mass strata, which ensures the stability of the roadway while saving the supporting costs. In the proposed unsymmetrical supporting scheme, additional cablebolts are installed in the direction where the failures and rock falls easily occur during the tunnelling of the roadway in the inclined rockmass strata. The proposed unsymmetrical supporting scheme is finally tested in a roadway excavated in the inclined rockmass strata of a coal mine. According to the continuous monitoring results in three months, it is found that the convergence between the roof and the floor of the roadway and that between the lateral walls become stable in about two months after the tunnelling of the roadway, and the separation of rock mass strata in both the rockbolt-reinforced zone and the cablebolt-reinforced zone is small, which indicates that the proposed unsymmetrical support scheme can ensure the stability of the roadway excavated in the inclined rockmass strata while keeping the supporting costs economical.
\end{abstract}

Keywords Inclined Strata, Similar Simulation, Un-symmetrical Support, Roadway

\section{Introduction}

In long-wall coal mining method, roadways are usually excavated along the bedding coal strata. The stability of these roadways is essential for continuously mining the underground coal rescources. As the mining depth increases, the in-situ stress becomes bigger and bigger. To make sure the stability of the roadways in great depths, the supporting system must be designed carefully according to the raised in-situ stress and the excavation-induced stress concentrations. Many researchers have made great contributions to this field (Xu, 1990), which results in the development of various kinds of theories for the stability of the surrounding rockmass such as the natural balance arch theory, caving arch theory, elastic theory, elastic-plastic theory, EDZ (excavation disturbed zone) theory, and key strata theory. The theories for the support action of the installed rockbolt and other support system include the hanging theory, combined beam theory and compression reinforcement theory. These theories are derived under specific conditions in specific mines, and correspondingly their applications are restricted by their hypothetical conditions. Moreover, due to the complex and variable geological conditions in mining practices, the pure theoretical method can seldom provide a satisfactory solution.

Some researchers have conducted physical model tests, especially similar simulation experiment, to study the stability of the roadways excavated in the bedding rockmass strata. In the similar simulation experiment, three-dimensional (3D) geomechanical models are built according to the similarity principles to study the stability of the tunnels in laboratories. Similar simulation experiment can visually imitate the stress concentration, deformation and failure of the surrounding rockmass induced by tunnel excavations and in-situ stresses. For example, He et al. (2010) studied the roadway excavation in the geologically horizontal strata at great depth using the similar simulation experiment. With the help of the infrared thermography and 
discrete Fourier transformation, they studied the response of the surrounding rock mass to the excavation process of the roadway, i.e. how the crack initiations and propagations and the pre-existing joints result in the collapse of the roadway during the excavation process. Meguid et al. (2008) reviewed the physical modelling including the similar simulation experiment of tunnelling in soft ground and summarized the advantages and disadvantages of each method available in literatures. Wu et al. (2009) built a similar simulation model using gypsum materials to study the mechanisms of rock burst during the excavation process of a roadway at great depths. According to their similar simulation experimental results, they developed a theoretical model for the zonal disintegration phenonmenon associated with rockburst based on the elasto-plastic analysis of the stress-strain behaviour of the surrounding rock mass using the improved Hoek-Brown strength criterion and the bilinear constitutive model. Liu et al. (2011) investigated the deformation of overlying coal seams above double-seam excavation using similar simulation experiments, which helped them draw the conclusion that due to the mining-induced stress redistribution, the pressure within overlying coal seams could be fully relieved to satisfy the statutory requirements of gas drainages.

Numerical methods have also been implemented to study the deformation and collapse process of the surrounding rockmass during the excavation of roadways under given geological conditions. The general-purpose finite element software ANSYS was used by Zhao et al. (2009) to study the rheological characteristics of a roadway excavated in a soft rockmass at great depth and the long-term mechanical behaviors of the support system of the roadway based on the generalized Kelvin creep model. Cai (2008) compared the simulated stress and yielding zone distributions in rockmasses around a circular tunnel using the explicit finite difference code FLAC and the implicit finite element code Phase 2. On the basis of his comparison, he stressed the influence of stress path on tunnel excavation response and made recommendation on how to choose appropriate tools and modeling strategies for tunnel excavation problems. The progressive failure processes of a circular opening excavated in a rock mass under biaxial compression and in a rock mass with pre-exisiting fractures are modelled by Wang et al. (2009) and Zheng et al. (2012), respectively, using the realistic failure process analysis code based on the finite element method. Recently, more and more researchers (Galli et al., 2004; Liu et al., 2008 and Lin et al., 2013) implemented full 3D finite element models to study the excavation process of both shallow and deep tunnels including the step-by-step excavation and support installation processes, the interaction between the surrounding rock mass and the support system, i.e. concrete/shotcrete lining and rockbolts, and the elasto-plastic behaviour of the surrounding rockmass and the installed support.

Each method reviewed above can reflect, to some extent, the stress redistribution and concentration, the deformation, and the crack initiation, propagation and coalescence in the surrounding rock mass during the excavation process of the roadway. In this paper, a 3D geomechanical physical model is firstly constructed in laboratory using the similar simulation method for the excavation of a roadway in inclined rockmass strata. The 3D geomechanical physical model is then loaded from the top bounday to visually reflect the behaviour of the roadway excavated in the inclined rockmass strata. After that, a support scheme is proposed for the roadway excavated in the inclined rockmass strata on the basis of the experiment results. Finally, the proposed support scheme for the roadway excavated in inclined rockmass is tested in the field to ensure the stability of the roadway under the real geological conditions.

\section{Inclined Rockmass Strata around the Roadway}

The prototype of the similar simulation experimemt is a roadway excavated in the No. $8^{\text {th }}$ mine of the Hebi Company of the Henan Coal Chemical Industry Group Co. Ltd, Henan Province, China. The roadway is excavated in the rockmass strata in the central region of the 3rd mining level of the mine, which is $530 \mathrm{~m}$ below the sea level. The roadway connects the dummy inclined shaft of ventilation at the southern end with the dummy inclined shaft of cable transportion at the northern end. The length of the roadway is $450 \mathrm{~m}$ and its design life is 30 years. The roadway is designed for coal transportion, ventilation, and mining workers' access to the No. 3003 working face.

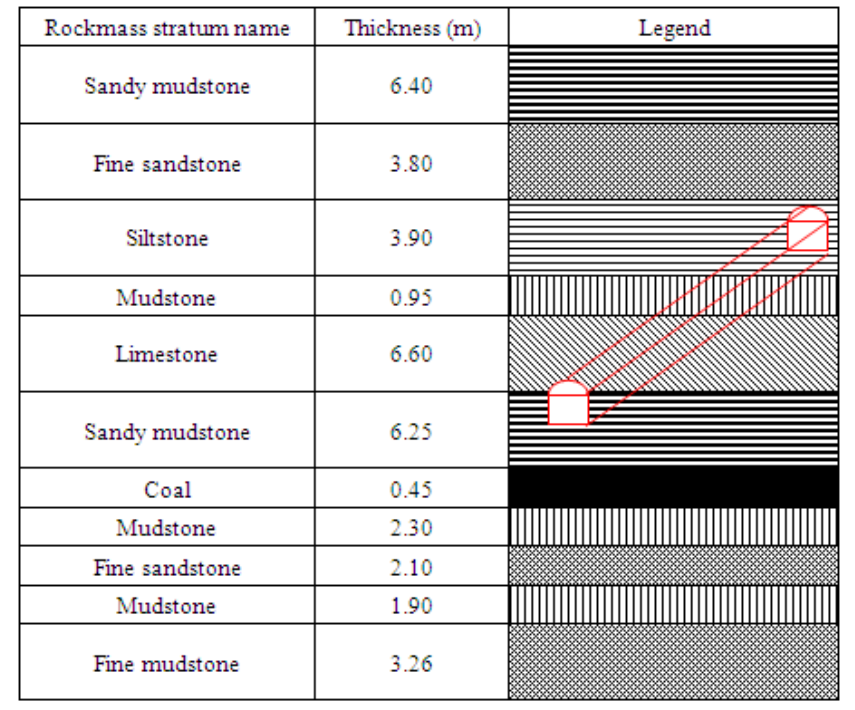

Figure 1. Columnar section of the rockmass strata surrounding the roadway to be excavated

The mine where the roadway is excavated has a simple monoclinal structure and the inclined angle of the rockmass strata is $25^{\circ}$. The roadway has a cover depth of $640 \mathrm{~m}$ and an inverse horse shoe shape with vertical lateral walls and 
semi-circle arch. The height of the vertical walls of the roadway is $1.3 \mathrm{~m}$, the width is $3.8 \mathrm{~m}$, and the total height is $3.2 \mathrm{~m}$. The roadway is first excavated in the sandy mudstone with a thickness of $6.25 \mathrm{~m}$ in average. As shown in Fig. 1, the immediate roof of the roadway is a stratum of hard limestone with a thickness of $6.6 \mathrm{~m}$ in average. The immediate floor is mainly a mudstone with a thin coal stratum. After that, the roadway passes through the limestone and mudstone, and is mainly excavated in the hard siltstone, as shown in Fig. 1. In this case, the roof and lateral sidewalls are fine sandstone and hard siltstone, respectively. The thicknesses of the fine sandstone and the hard siltstone are $3.8 \mathrm{~m}$ and $3.9 \mathrm{~m}$, respectively. The immediate floor is the soft mudstone with a thickness of $0.95 \mathrm{~m}$.

\section{Similar Material Simulation Experiment}

According to the similar theory $(\mathrm{Li}, 1987)$, the materials adopted in the similar simulation experiment must have the physical-mechanical properties similar to those of the prototypes, which requires similarities hold true for the geometries, densities, strengthes, stresses, forces, time, etc, of the materials in the prototypes and those used in the similar simulation experiment.

\subsection{Selection of Similar Ratio}

The similar ratio should be chosen on the basis of the size of the model frame, the size of the prototype to be modelled, and the capacity of the loading system. Generally, the possible biggest similar ratio should be selected so that the protoype can be modelled as accurately as possible and the experimental results can realistically reflect what happen in the prototype. Following these considerations, the similar ratio of the sizes of the similarity model and the prototype is chosen as 1:20, and that of the bulk density is 1:1.5. Correspondingly, the similar ratios of the strength / stress, load, and Poisson's ratio can be calculated, which are 1:30, $1: 12000$, and $1: 1$, respectively. The size of the similar simulation model is $1600 \mathrm{~mm}$ (length) $\times 1600 \mathrm{~mm}$ (width) $\times$ $400 \mathrm{~mm}$ (thickness), which corresponds to $32 \mathrm{~m}$ (length) $\times$ $32 \mathrm{~m}$ (width) $\times 8 \mathrm{~m}$ (thickness) of the rockmass in field.

\subsection{Selection of Similar Material}

The similar material is made of water, cement, gypsum, sand and borax. Among them, the sand is the main component, the cement and the gypsum are used as bonding materials, and the borax is working as retarder. According to the physical-mechanical properties of the rock mass surrounding the roadway, the quantity of each component is calculated, which is summarized into Table 1 . These components are then mixed with each other to model the rock mass strata in the field. In Table 1, the mixture ratio stands for that of the weights of sand : cement : gypsum. For each rock mass stratum, the total quantity of mixture used in the similar simulation experiment is first calculated according to the thickness and density of the rock mass strata, and the width and similar ratio of the similar simulation model. The quanities of the sand, cement and gypsum are then calculated according the mixture ratio. For example, for the sandy mudstone, the mixture ratio is $90: 5: 5$, which means the quantities of the sand, cement and gypsum are $0.9,0.05$ and 0.05 , respectively, times the total quantity. The quantity of the water is 0.1 times the total quantity while that of the borax is 0.01 times the quantify of the water.

Table 1. Mixture ratio and material quantity for the similar material simulation experiment

\begin{tabular}{ccccccc}
\hline Strata & $\begin{array}{c}\text { No. of } \\
\text { ratio }\end{array}$ & Sand/kg & cement/kg & gypsum $/ \mathrm{kg}$ & water $/ \mathrm{kg}$ & borax $/ \mathrm{kg}$ \\
\hline Sandy mudstone & $90: 5: 5$ & 221.36 & 12.30 & 12.30 & 24.60 & 0.25 \\
Fine sandstone & $80: 5: 5$ & 170.38 & 21.30 & 21.30 & 21.30 & 0.21 \\
Siltstone & $90: 3: 7$ & 217.39 & 7.25 & 16.91 & 24.15 & 0.24 \\
Mudstone & $90: 5: 5$ & 42.34 & 2.35 & 2.35 & 4.70 & 0.05 \\
Limestone & $70: 5: 5$ & 294.50 & 63.11 & 63.11 & 42.07 & 0.42 \\
Sandy mudstone & $90: 5: 5$ & 291.13 & 16.17 & 16.17 & 32.35 & 0.32 \\
Mudstone & $90: 5: 5$ & 99.46 & 5.53 & 5.53 & 11.05 & 0.11 \\
Fine sandstone & $80: 5: 5$ & 62.23 & 7.78 & 7.78 & 7.78 & 0.08 \\
Mudstone & $90: 5: 5$ & 53.73 & 2.98 & 2.98 & 5.97 & 0.06 \\
Fine sandstone & $80: 5: 5$ & 68.64 & 8.58 & 8.58 & 8.58 & 0.09 \\
\hline
\end{tabular}




\subsection{Similar Simulation Experiment Setup}

The similar simulation experiment is conducted using the YDM-E physical model testing device developed jointly by Henan Polytechnic University and the Third Institute of Engineering, Army of General Staff of PLA, which is shown in Fig. 2. The physical model testing device consists of five components, namely, model frame, mould for testing samples, transportation vehicle, hydraulic control system and data acquisition system. The induced stresses are logged using the YJZ-16A intelligence digital stress instrument developed by Beijing Tairui Jinxing Instrument Ltd. During the model preparation, strain gauges are buried into the model, as shown in Fig. 3, which are then calibrated to determine the corresponding stress to each unit of strain. After each loading, it is required to wait $30 \mathrm{~min}$ before the measurement is conducted so that the stress transfer process is completed at the time of the measurement. The data from each measurement point are converted by the YJZ-16A intelligent digital strain instrument into digital values, which can be directly read from computers. The obtained data are finally converted into the actual stresses in the rockmass according to the stress and strain relation calibrated previously and the similarity ratio.

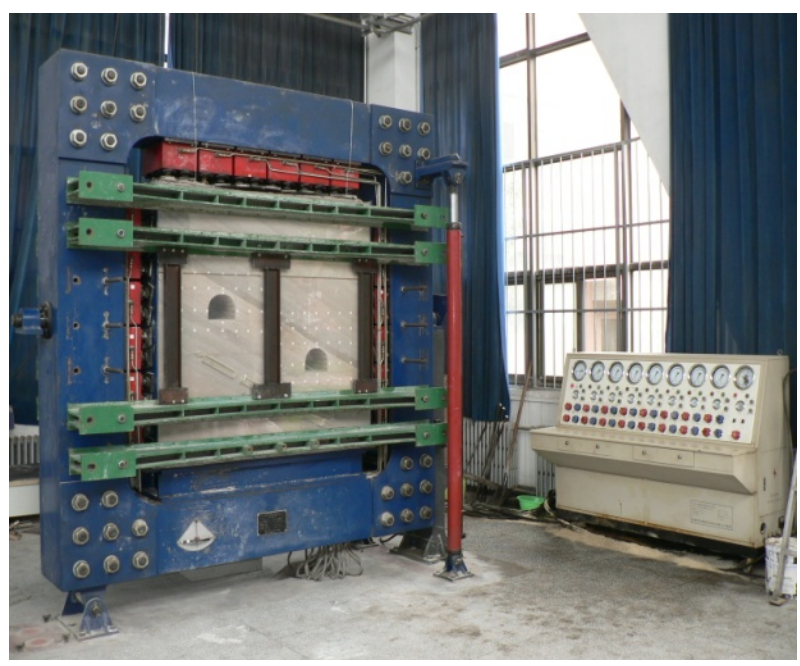

Figure 2. Similar simulation experimental setup

Since the rockmass strata is inclined to the horizontal direction at an angle of $25^{\circ}$, the model frame is rotated $25^{\circ}$ for the convenience during the model preparation. The similar materials prepared according to Table 1 are then filled into the model frame layer by layer and densified using a metal block. Each layer is separated by wood powder or mica powder from the adjacent layers. If the thickness of a layer is relatively big, the layer is filled through a few thin sub-layers. Finally, the model frame is brought back to its normal position. The prepared final similar simulation model is shown in Fig. 2. As can be seen from Fig. 2, there are two similar simulation models installed in the model frame: the roadway in the left model is supported while that in the right model is unsupported. The support system of the roadway in the left model includes the shotcrete lining and rockbolts depicted in Fig. 7, which are symmetrical to the central line of the roadway, but does not include the unsymmetrical cablebolts in Fig. 7. The prepared models are left in the model frame to dry for 15 days before the similar simulation experiment should begin.

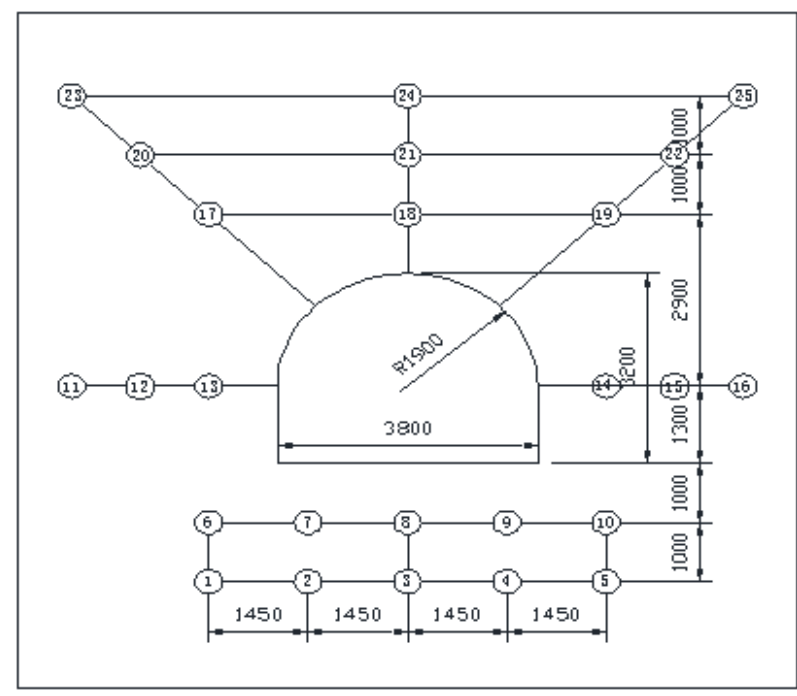

Figure 3. Distribution of monitoring points in the similar simulation model

\section{Experimental Results}

During the similar simulation experiment, vertical loads are applied on the top boundary of the model through the hydraulic control system of the YDM-E physical model testing apparatus and the lateral sides are restricted to move in the horizontal direction, which applies a reaction force (i.e. passive loading) in the lateral sides of the model. Fig. 4 records the deformation and failure processes of the roadways when the model is subjected to various loads. Since the characteristics of the deformation and failure processes of the roadway supported using symmetrical shotcrete lining and rock bolt are similar to those of the unsupported roadway. Only the deformation and failure processes of the unsupported roadway are described here in detail. It can be seen from Fig. 4 that, as the load increases to $6.82 \mathrm{MPa}$, cracks are firstly initiated in the rock mass located in the right-upper corner of the roadway, i.e. about $45^{\circ}$ from the horizontal direction (Fig. 4 b). More and more cracks nucleate there as the load increases (Fig. 4 c). When the load is increased to $11.34 \mathrm{MPa}$, the rock located in the right-upper corner of the roadway detaches from the roof and falls into the roadway (Fig. 4 d). With the load further increasing, more and more rock falls from there (Fig. 4 e). Finally, when the load increases to $15.86 \mathrm{MPa}$, the roadway is destroyed completely, as shown in Fig. $4 \mathrm{f}$. 


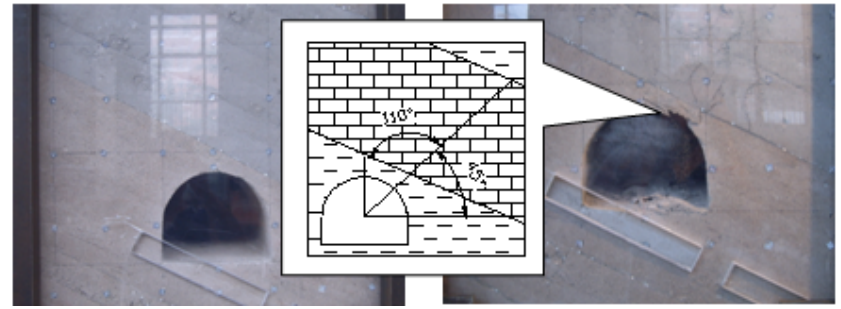

a) $2.3 \mathrm{MPa}$

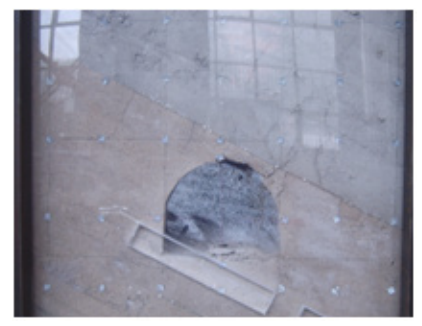

c) $9.08 \mathrm{MP} \mathrm{a}$

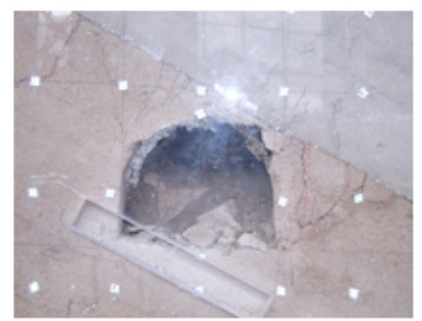

e) $13.6 \mathrm{MP} \mathrm{a}$ b) $6.82 \mathrm{MPa}$

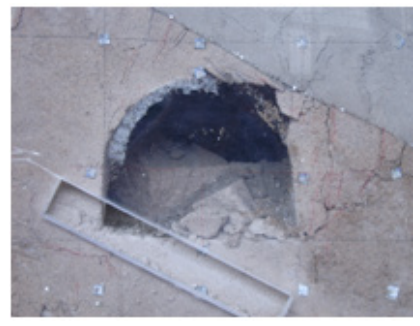

d) $11.34 \mathrm{MPa}$

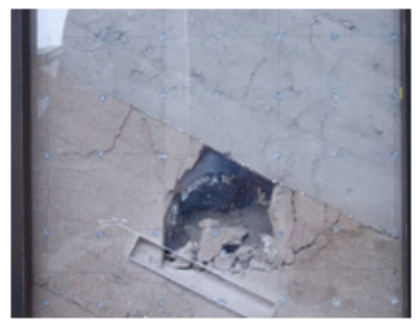

f) $15.86 \mathrm{MPa}$
Figure 4. Failure process of the roadway as the applied load increases

The stress distribution in the rock mass surrounding the roadway is the main factor controlling the deformation and failure process of the roadway. As introduced above, the strain gauges are buried into the similar simulation model to $\log$ the stresses at the measurement points depicted in Fig. 3 using the YJZ-16A intelligence digital stress instrument, which can be used to investigate evolutional laws of the stresses at the measurement points as the applied load increases. Fig. 5 records the variation of the vertical and horizontal stresses monitored at the key measuring points along the central line of the roadway and the $45^{\circ}$ inclined line. In Fig. 5, the compressive stress is regarded as negative and the tensile stress is regarded as positive. As shown in Fig. 3, the measuring point $\mathrm{A} 3$ is located at $2 \mathrm{~m}$ from the floor of the roadway along the central line of the roadway. The vertical stress at A3 is compressive at the beginning of the loading (Fig. 5 a). As the load increases to $10 \mathrm{MPa}$, the vertical stress at A3 changes to become tensile from the original compressive stress (Fig. 5 a) although the horizontal stress at A3 has not changed obviously (Fig. 5 c) during the loading process since it is $2 \mathrm{~m}$ away from the roadway opening (Fig. $3)$. Thus, the floor of the roadway has the tendency of upheave. The monitoring point A8 is also located at the floor of the roadway but it is located at $1 \mathrm{~m}$ above A3 along the central line. It can be seen from Fig. 5 a) and c), the variation of the vertical and horizontal stresses at A8 is similar to those at $\mathrm{A} 3$ at the beginning of the loading. However, as the load increases to $10 \mathrm{MPa}$, the tensile stress at A8 increases rapidly and correspondingly the floor of the roadway heaves up, which can also be observed in Fig. 4. The monitoring points A18, A21 and A24 is located at the roof of the roadway along the central line. It can be seen from Fig. 5 a) and c) that the vertical stresses at A18 and A24 and the horizontal stresses at A21 vary rapidly at the later stage of the loading, especially at the measuring point $\mathrm{A} 18$, the vertical stress repeatly reverses. The reason is probably that A18 is located at the roof of the roadway closest to the opening. Moreover, the falling of rock into the opening cause the separation of layers around the measuring point A18, which makes the data there become invalid and the tensile stresses there continuously be released and accumulated. That is why the vertical stress at A18 in Fig. 5 a) shows the obvious oscillation during the collapse process of the roadway. The measuring points A19, $\mathrm{A} 22$, and A25 are located in the right-upper roof of the roadway, i.e. $45^{\circ}$ from the horizontal direction. It can be seen from Fig. 5 b) and d), at the later stage of the loading, there are big tensile stresses in both horizontal and vertical directions at the monitoring point A19, which indicates that the damage and failure easily occur there. This is consistent with the rock falls photographed in Fig. 4. The falling of rock into the opening causes the separation of layers around the measuring point A19, which makes the measuring point A19 becomes invalid after the rock falls. That is why big changes of horizontal and vertical stresses at the measuring point A19 are recorded after the rock falls. In comparison, both vertical and horizontal stresses monitored at the measuring point A25 remain compressive since A25 is much further away from the opening of the roadway than A19. The measuring point A22 is located between A19 and A25. Correspondingly, the stresses at A22 are between those at A19 and A25 

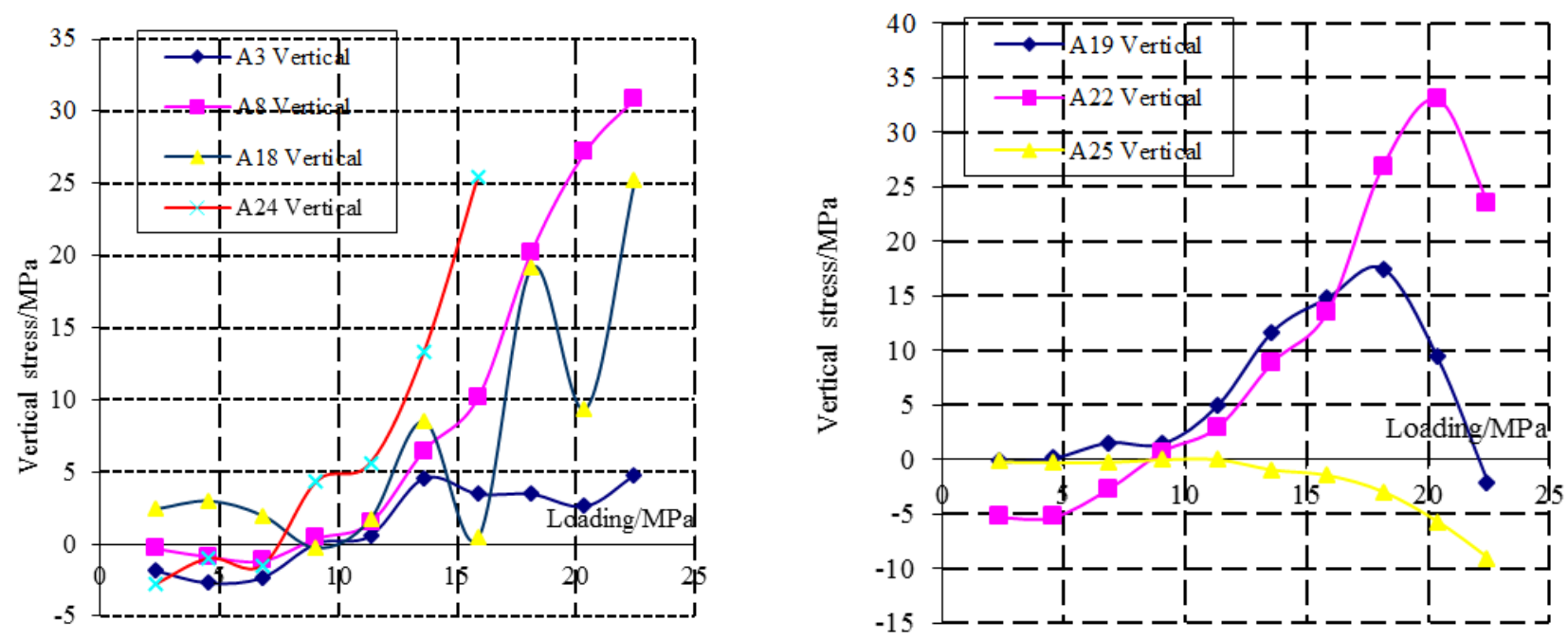

a) Variation of vertical stresses at the monitoring points along the central line

b) Variation of vertical stresses at the monitoring points along the $45^{\circ}$ line

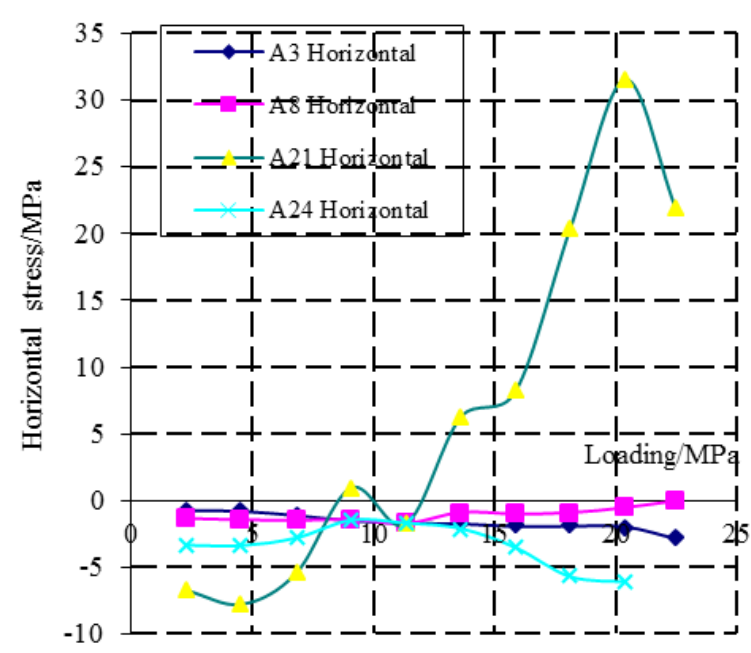

c) Variation of horizontal stresses at the monitoring points along the central line

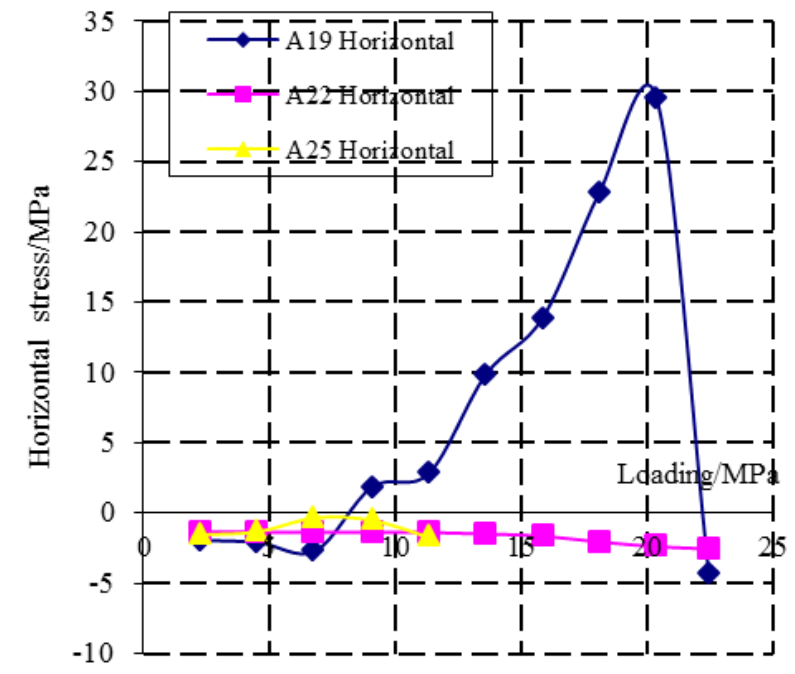

d) Variation of horizontal stresses at the monitoring points along the $45^{\circ}$ line

Figure 5. Variation of the vertical and horizontal stresses in the rockmass surrounding the roadway as the applied load increases (the labels of the monitoring points correspond to those depicted in Fig. 3)
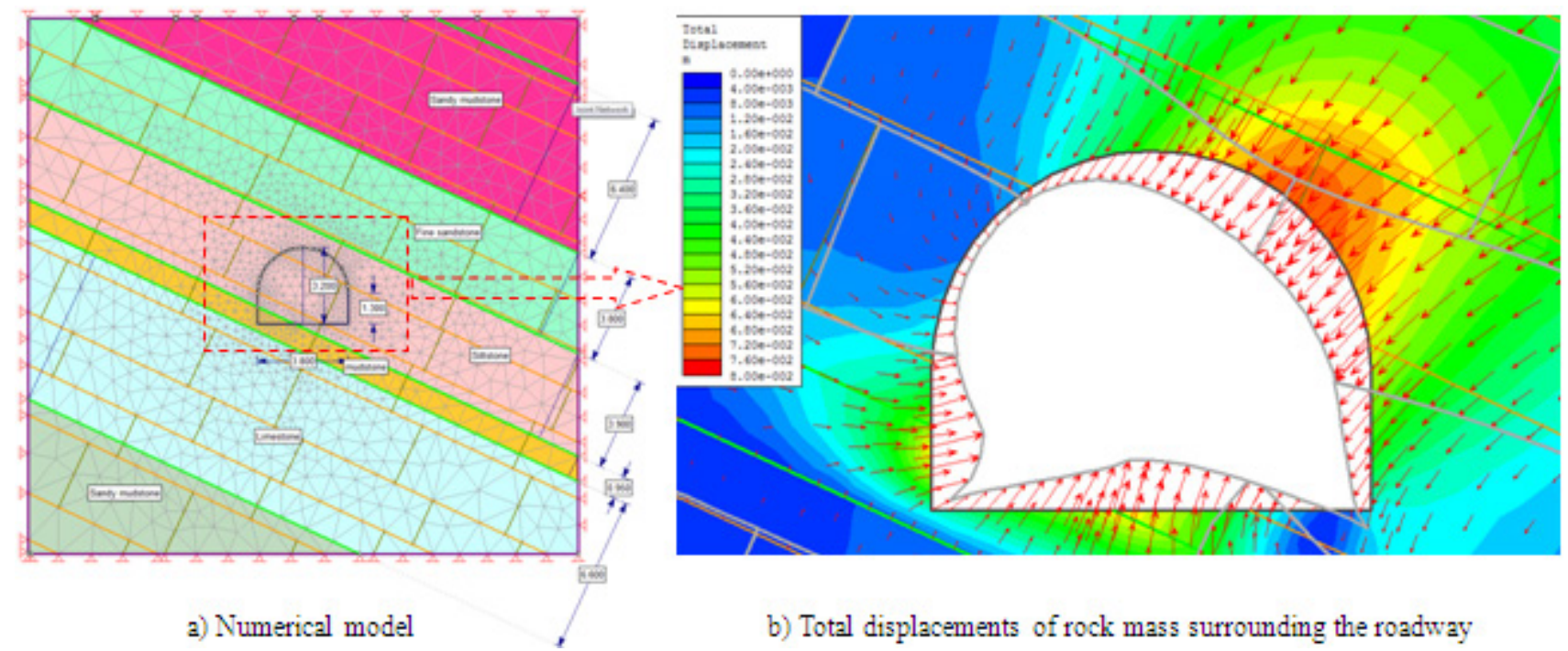

b) Total displacements of rock mass surrounding the roadway

Figure 6. Numerical modelling of the deformation process of the roadway as the applied load increases to $11.34 \mathrm{MPa}$, which corresponds to the loads in Fig. 4 d) 
Therefore, it can be seen from the experimental and numerical results presented above that due to the inclined orientation of the rockmass strata, the roadway is loaded unsymmetrically, which results in that the cracks are first nucleated and initiated at the right-upper corner of the roadway and then propagate and coalesce there resulting in rock falls there and the unsymmetrical failure pattern of the roadway. Moreover, it is found from the similar simulation experiment that even if the roadway is supported using symmetrical shotcrete lining and rock bolts, there are few differences in the observed deformation and failure patterns of the roadway. To ensure the stability of the roadway, an unsymmetrical support scheme may be designed for the roadway to save the supporting costs. The unsymmetrical support scheme can be implemented using cablebolts since each cablebolt can only reinforce the rockmass surrounding the installing location. The direction of the installed cablebolts should be consistent with the direction where the surrounding rock mass may easily fail due to the unsymmetrical loads caused by the inclined rockmass strata, i.e. the about 45 degree from the horizontal direction for this study. However, the supporting direction depends on the factors such as the inclined angle of the rockmass strata, physical-mechanical properties of the rockmasses, and in-situ stresses, where further studies are needed.

In order to validate the similar simulation experimental results, a simple finite element model is constructed using Rocscience Phase2D, as shown in Fig. 6 a. The roadway is then excavated in the rock wass with various in-situ stresses to observe the deformaton process of the roadway. Fig. 6 depicts the modelled total displacement of the rock mass surrounding the roadway excavation. It can be seen from Fig. $6 \mathrm{~b}$ that, when the in-situ stress increases to $11.34 \mathrm{MPa}$, which corresponds to the loads in Fig. 4 d, the rock mass located in the right-upper corner of the roadway moves greatest towards the roadway excavation and the floor heaves up. It is obvious that the characteristics of the modelled deformation process of the roadway support those of the deformation and failure processes of the roadway observed in the similar simulation experiment although more sophisticated numerical analyses may be needed.

\section{Design of Unsymmetrical Support Scheme}

According to the results from the similar simulation experiments introduced above, an unsymmetrical support scheme is adopted to support the roadway excavated in the inclined rockmass strata. Rockbolts and cablebolts are used as the main reinforing elements. The selected rockbolts are screw thread steel anchor with a diameter of $\varnothing 20 \mathrm{~mm}$ and a length of $2000 \mathrm{~mm}$, which are installed symmetrically along the opening of the roadway with a spacing grid of $800 \mathrm{~mm} \times$ $800 \mathrm{~mm}$, as shown in Fig. 7 a. The rockbolts are fixed using 2 volumes of CK2335 resin grouting agents. As shown in Fig. 7 a, the layout of the cablebolts is unsymmetrical: one is installed at the direction of $45^{\circ}$ from the horizontal direction, which is the main direction where the cracks are first nucleated and initiated, and propagate and coalesce resulting in the rock falls. The other cablebolt is installed at the direction of $10^{\circ}$ away from the central line of the roadway opening, which is the location where the rock falls finally propagate to. The chosen cablebolts are the low relaxation steel strand $(1 \times 7$ wires $)$ with a diameter of $\emptyset 17.18 \mathrm{~mm}$ and a length of $7000 \mathrm{~mm}$. The cablebolts are fixed using 1 volume of CK2335 and 3 volumes of Z2335 resin grouting agents. In sum, the rockbolts are installed symmetrical to the central line of the roadway opening while the cablebolts are mainly installed in the regions where the major rockfalls are expected to occur according to the similar simulation experiments, as shown in Fig. 7 a. Along the axis of the roadway, cablebolts are installed in every two rows of rockbolts and thus the spacing of cablebolts is $1600 \mathrm{~mm}$ since the rockbolts are distributed in a spacing grid of 800 $\mathrm{mm} \times 800 \mathrm{~mm}$.

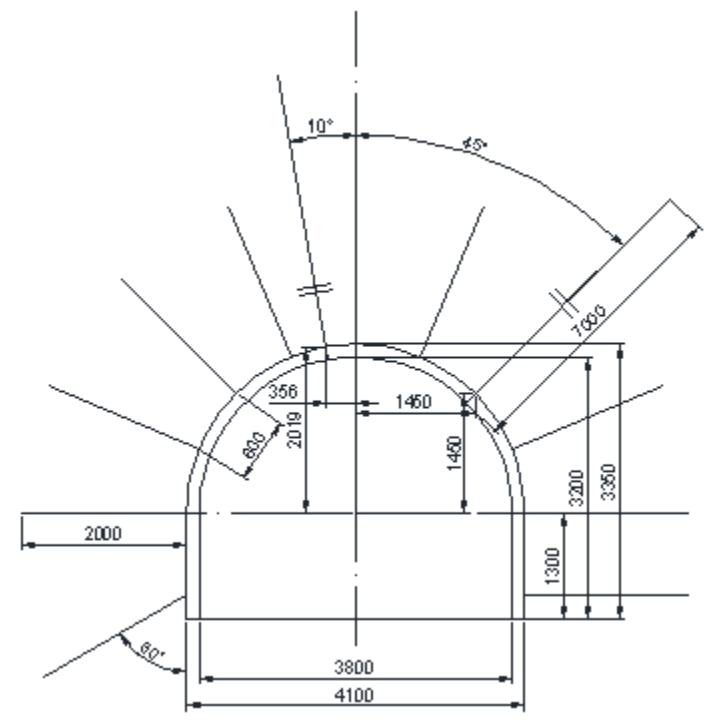

a) Unsymmetrical support system

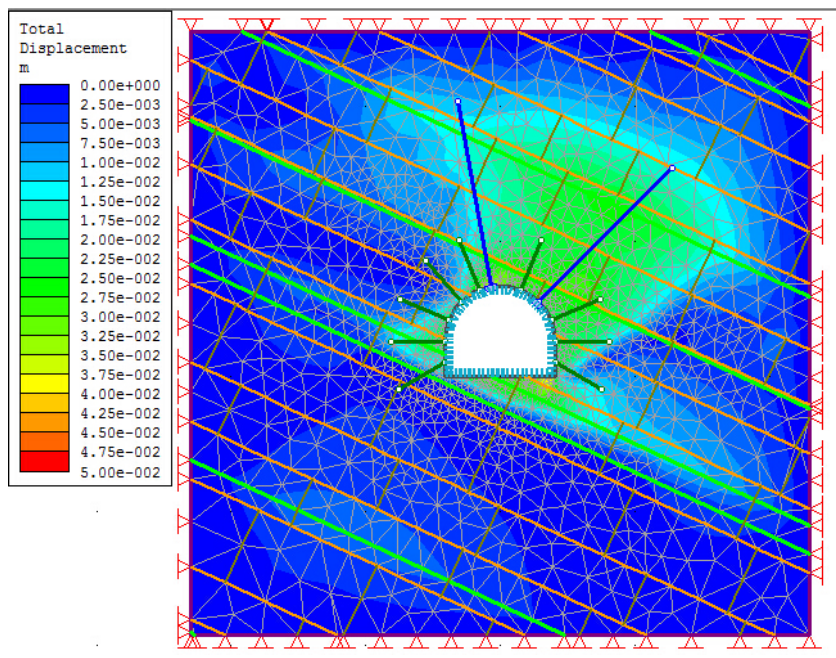

b) Numerical validation of the unsymmetrical support system

Figure 7. Unsymmetrical support design for a roadway excavated in inclined rock mass strata 
To check whether the unsymmetrical support scheme can satisfy the requirements, a simple finite element analysis is conducted again using Rocscience Phase2D to analyze the deformation behaviour of the roadway supported using the unsymmetrical support system, as shown in Fig. 7 b. Through comparing the total displacement fields depicted in Fig. $6 \mathrm{~b}$ and Fig. 7 b, it is obvious that the unsymmetrical support system successfuly limits the deformation and then failure of the rock mass in the right-upper corner of the roadway excavated in the inclined rockmass strata.

\section{Field Experiments}

Field experiments are conducted in the No. 3003 roadway excavated in the inclined rockmass strata in the No. 8th Coal Mine of Hebi Mining Corporation, Henan Province, China. The roadway is located on the top of limestone and excavated in mudstone and siltstone. As shown in Fig. 1, the mudstone has a thickness of $0.95 \mathrm{~m}$, which is located at the floor of the excavated roadway. The roof and lateral walls of the roadway are harder siltstone with an average thickness of $3.9 \mathrm{~m}$ and fine sandstone with an average thickness of $3.8 \mathrm{~m}$, respectively. The cover depth of the roadway is $640 \mathrm{~m}$ from the ground surface. In light of the similar simulation experimental results, an unsymmetrical support scheme has been designed in Section 5 for the No. 3003 roadway. During the field experiments, the convergence of the roadway between the roof and floor and that between the lateral walls are monitored. Moreover, a few measuring points are installed in the areas reinforced by rockbolts and cablebolts to monitor the displacements there, too.6.1. Convergence between the roof and floor of the roadway and that between the lateral walls.

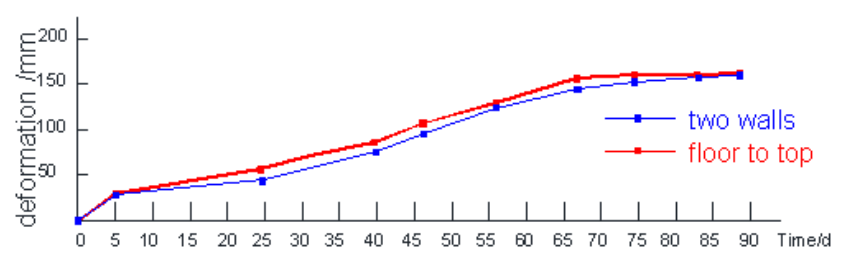

Figure 8. Convergence between the roof and floor and that between the lateral walls of the roadway as the time increases

During the tunnelling of the roadway, the displacements at the roof, floor and lateral walls of the roadway are monitored periodically to record the convergence of the roadway opening. After continuously monitoring for about 3 months, the variational law of the convergence of the roadway opening is basically revealed. Fig. 8 depicts the convergence between the roof and floor and that between the lateral walls of the roadway according to the monitored results at a few measuring points. It can be seen that during the first 5 days, i.e. immediately after the tunnelling of the roadway, the opening of the roadway convergences rapidly and the observed deformation is signficant. The deformation rate slows down after 5 days and the deformation gradually increases from 5 days till about 65 days. The convergence becomes basically stable in about two months after the tunnelling of the roadway. In the third month during monitoring, almost no convergence is observed between the floor and roof of the roadway opening and little convergence is observed between the lateral walls of the roadway opening. On the 90th day of the monitoring, the recorded maximum convergence between the roof and floor and that between the lateral walls are $160.9 \mathrm{~mm}$ and $170.43 \mathrm{~mm}$, respectively. The rate of the convergence between the roof and floor of the roadway and that between the lateral walls are $0.08 \mathrm{~mm}$ per day and $0.09 \mathrm{~mm}$ per day, respectively, in average in the last month of the monitoring, which reveals that the roadway is now stable and the designed unsymmetrical support scheme satistifies the supporting requirements of the roadway.

\subsection{Roof Separations Monitored Along the Axis of the Roadway}

During the field experiments, two types of additional measuring points are installed in the surrounding rockmass $1.9 \mathrm{~m}$ and $6.9 \mathrm{~m}$ from the excavation profile of the roadway along the axis of the roadway, which are named as shallow and deep measuring points, respectively. Since the lengths of the installed rockbolts and cablebolts are $2000 \mathrm{~mm}$ and 7000 $\mathrm{mm}$, respectively, the installed shallow and deep measuring points are actually used to monitor the displacement and separation of the rockmass strata in the rockbolt-reinforced and cablebolt-reinforced areas, respectively. Since the monitored rock mass stratum separation rate is very small, only the final values of the separations of the rockmass strata at the shallow and deep monitoring points are listed in Table 2. As can be seen from Table 2, the maximum separation of the rockmass strata inside the rockbolt-reinforced zone along the axis of the roadway is $5 \mathrm{~mm}$, the minimum separation is 2 $\mathrm{mm}$, and the average separation is $3.75 \mathrm{~mm}$. In the cablebolt-reinforced zone, the maximum separation is $12 \mathrm{~mm}$, the minimum separation is $7 \mathrm{~mm}$, and the average separation is $9.75 \mathrm{~mm}$. Thus, it is obvious that the separation of the rockmass strata in the rockbolt-reinforced zone is smaller than that in the cablebolt-reinforced zone. Moreover, it is obvious that all of the monitored separations are small, which satisfies the requirements of the roof separations specified in the mining legislations of the mine. Correspondingly, it is concluded that the roadway is stable, which reveals that the proposed unsymmetrical support scheme can ensure the stability of the roadway excavated in the inclined rockmass strata. 
Table 2. Roof separations monitored at various locations along the axis of the roadway

\begin{tabular}{|c|c|c|c|c|c|c|c|c|}
\hline \multirow{2}{*}{$\begin{array}{l}\text { Testing point } \\
\text { number }\end{array}$} & \multicolumn{2}{|c|}{ No. 1} & \multicolumn{2}{|c|}{ No. 2} & \multicolumn{2}{|c|}{ No. 3} & \multicolumn{2}{|c|}{ No. 4} \\
\hline & Shallow & Deep & Shallow & Deep & Shallow & Deep & Shallow & Deep \\
\hline Initial/mm & 0 & 0 & 0 & 0 & 0 & 0 & 0 & 0 \\
\hline $\mathrm{Final} / \mathrm{mm}$ & 3 & 7 & 5 & 11 & 2 & 9 & 5 & 12 \\
\hline Abscission/mm & 3 & 7 & 5 & 11 & 2 & 9 & 5 & 12 \\
\hline
\end{tabular}

\section{Conclusions}

In this study, 3D similar material simulation experiments are first conducted to study the stress distribution and failure process of a roadway excavated in the inclined rockmass strata. For the roadway excavated in the rockmass strata with an inclinded angle of $25^{\circ}$, it is found that cracks are initiated firstly in the rockmass located in the right-upper roof of the roadway, i.e. about $45^{\circ}$ from the horizontal direction. As the applied vertical load increases, more and more cracks nucleate, propagate and coalesce there. The rock located in the right-upper roof of the roadway then detaches from the roof and falls into the roadway resulting in the collapse of the roadway. On the basis of the similar material simulation experimental results, an unsymmetrical supporting scheme is then proposed to use rockbolts and cablebolts to support the roadway excavated in the inclined rockmass strata ensuring the instability of the roadway while keeping the supporting costs economical. In the proposed unsymmetrical supporting scheme, additional cablebolts are installed in the direction where the failures and rock falls easily occur during the tunnelling of the roadway in the inclined rockmass strata. The proposed unsymmetrical supporting scheme is finally tested in a roadway excavated in the inclined rockmass strata in a coal mine. During the field experiments, several measuring points are distributed in the excavation profile of the roadway and buried in the surrounding rock mass to monitor the convergence of the roadway and the rockmass strata separation in the rockbolt-reinforced zone and the cablebolt-reinforce zone, respectively. According to the continuously monitoring results in three months, it is found that the convergence between the roof and floor of the roadway and that between the lateral walls become stable in about two months after the tunnelling of the roadway, and the separation of rock mass strata in both the rockbolt-reinforced zone and the cablebolt-reinforced zone is small, which indicates that the proposed unsymmetrical support scheme can ensure the stability of the roadway excavated in the inclined rockmass strata while keeping the supporting costs economical although further studies may be needed for the stability of the roadway during vehicle movement.

\section{REFERENCES}

[1] Cai M. 2008. Influence of stress path on tunnel excavation response - Numerical tool selection and modeling strategy. Tunnelling and Underground Space Technology 23: 618-628

[2] Galli G., Grimaldi A. and Leonardi A. 2004. Three-dimensional modelling of tunnel excavation and lining. Computers and Geotechnics 31: 171-183

[3] He M.C., Gong W.L., Zhai H.M. and Zhang H.P. 2010. Physical modeling of deep ground excavation in geologically horizontal strata based on infrared thermography. Tunnelling and Underground Space Technology 25: 366-376

[4] Li H.C. 1987. Similar simulation experiments of mine pressure. China University of Mining and Technology Press, Xuzhou, China

[5] Lin P., Zhou Y., Liu H.Y. and Wang C. 2013. Reinforcement and stability analysis of large-span tailrace bifurcation tunnel with irregular geometry. Tunnelling and Underground Space Technology 38: 189-204

[6] Liu H.Y., Small J.C. and Carter J.P. 2008. Full 3D modelling for effects of tunnelling on existing support systems in the Sydney region. Tunnelling and Underground Space Technology 23: 399-420

[7] Liu Y.K., Zhou F.B., Liu L., Liu C. and Hu S.Y. 2011. An experimental and numerical investigation on the deformation of overlying coal seams above double-seam extraction for controlling coal mine methane emissions. International Journal of Coal Geology 87(2): 139-149

[8] Meguid M.A., Saada O., Nunes M.A. and Mattar J. 2008. Physical modeling of tunnels in soft ground: A review. Tunnelling and Underground Space Technology 23: 185-198

[9] Wang S.Y., Sloan S.W., Sheng D.C. and Tang C.A. 2012. Numerical analysis of the failure process around a circular opening in rock. Computers and Geotechnics 39: 8-16

[10] Wu H., Guo Z.K., Fang Q., Zhang Y.D. and Liu J.C. 2009. Mechanism of zonal disintegration phenomenon in enclosing rock mass around deep tunnels. Journal of Central South University of Technology. 16 (2): 303-311

[11] Xu X.H. 1990. Mining Handbook Vol. 2. China Metallurgical Industry Press. ISBN: 7502406484

[12] Zhao T.B., Ma Y.H., Tan Y.L., An Y.L. and Chen Y.J. 2009. Creep characteristic simulation of deep soft rock roadway and long-term mechanical analysis of lining support. Journal of science \& engineering 15(2): 193-196

[13] Zheng X.P., Cao P. and Pu C.Z. 2012. Numerical simulation on rock-similar material with multi-fractures under uniaxial compression, Chinese Science Bulletin, 57 (13): 1106-1111 